\title{
Interventionen praxisnah simulieren
}

Für Studierende aus dem „Hellste Köpfe“Programm hält der 98. RöKo etwas ganz besonderes bereit. In zweistündigen Hands on-Workshops werden die Teilnehmerinnen und Teilnehmer spielerisch an die interventionelle Neuro-/Radiologie herangeführt. Das Besondere: Unter Anleitung können in Kleinstgruppen praktische Übungen (z. B. zu Beckenarterien, vaskulärem Trauma-Management oder Schlaganfall) an mehreren elektronischen Simulatoren selbst durchgeführt werden. Den Studenten wird so nicht nur fallbasiertes Wissen vermittelt, sondern Sie haben auch die Gelegenheit, dieses Wissen vor Ort anzuwenden. Erfahrene Tutoren gehen dabei unmittelbar auf Fragen der Teilnehmer ein und können bei den simulierten Interventionen Unterstützung leisten.

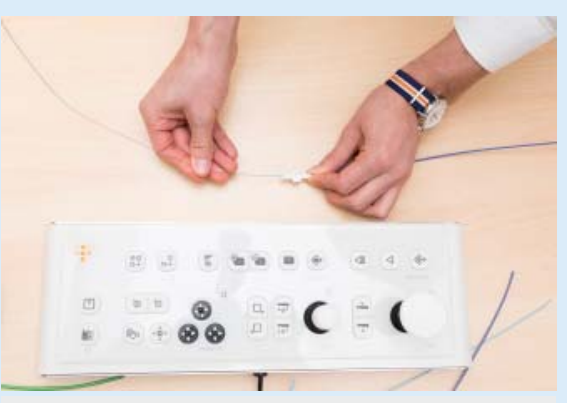

Interventionen lassen sich am Simulator praxisnah durchführen - wie hier auf dem Radiologiekongress Nord 2017.

Ermöglicht wird dieses besondere LernAngebot für Studenten durch das schwedische Unternehmen Mentice, das hierfür insgesamt vier Simulatoren inklusive technischen Support bereitstellt.

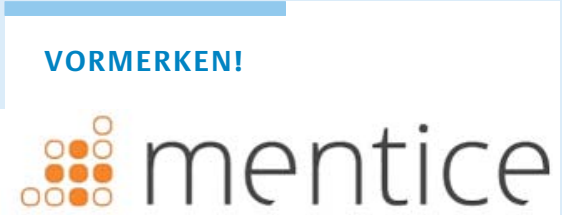

MITTWOCH , 24.05.2017, 16:15 bis 18:15 Uhr, WORKSHOP-BEREICH II WS STUD 5: Schnupperkurs Interventionelle (Neuro-)Radiologie FREITAG , 26.05.2017, 08:00 bis 10:00 Uhr, WORKSHOP-BEREICH II WS STUD 6: Schnupperkurs Interventionelle (Neuro-)Radiologie

(Die Kurse sind teilnehmerbegrenzt. Eine Anmeldung ist nur über das OnlineAnmeldeportal möglich) 